University of Wollongong

Research Online

Australian Institute for Innovative Materials -

Papers

Australian Institute for Innovative Materials

$1-1-2018$

In situ construction of yolk-shell zinc cobaltite with uniform carbon doping

for high performance asymmetric supercapacitors

Xiaoya Chang

Nankai University

Lei Zang

Nankai University

Song Liu

Nankai University

Mengying Wang

Nankai University

Huinan Guo

Nankai University

See next page for additional authors

Follow this and additional works at: https://ro.uow.edu.au/aiimpapers

Part of the Engineering Commons, and the Physical Sciences and Mathematics Commons

Research Online is the open access institutional repository for the University of Wollongong. For further information contact the UOW Library: research-pubs@uow.edu.au 


\title{
In situ construction of yolk-shell zinc cobaltite with uniform carbon doping for high performance asymmetric supercapacitors
}

\author{
Abstract \\ Zinc cobaltite (ZnCo 204 ) is a promising material for supercapacitors with appreciable theoretical \\ capacitance. However, it suffers from poor electrical conductivity and large volume expansion during \\ charge-discharge processes. In this work, a novel material, ZnCo 204 /C microspheres in a yolk-shell \\ structure, is fabricated by a facile refluxing process in combination with a calcination treatment. Carbon is \\ in situ formed via the pyrolysis of polyvinyl pyrrolidone and uniformly dispersed both in the core and the \\ shell. Benefiting from the unique structure and the synergistic effect of the two components, this material \\ exhibits remarkable electrochemical properties such as high specific capacitance ( $1821 \mathrm{~F} \mathrm{~g} \mathrm{-1} \mathrm{at} 5 \mathrm{~A} \mathrm{~g}-1$ \\ ), excellent rate performance, and superior cycling stability (no capacitance loss over 9000 cycles). The \\ assembled asymmetric supercapacitor coupled with an active carbon anode can deliver a high energy \\ density of $45.9 \mathrm{~W} \mathrm{~h} \mathrm{~kg}-1$ at a power density of $700 \mathrm{~W} \mathrm{~kg}-1$ with an excellent cycling stability (i.e. a \\ capacitance retention rate over $95 \%$ after 9000 cycles).

\section{Disciplines} \\ Engineering | Physical Sciences and Mathematics

\section{Publication Details} \\ Chang, X., Zang, L., Liu, S., Wang, M., Guo, H., Wang, C. \& Wang, Y. (2018). In situ construction of yolk-shell \\ zinc cobaltite with uniform carbon doping for high performance asymmetric supercapacitors. Journal of \\ Materials Chemistry A, 6 (19), 9109-9115.
}

\section{Authors}

Xiaoya Chang, Lei Zang, Song Liu, Mengying Wang, Huinan Guo, Caiyun Wang, and Yijing Wang 


\title{
In situ construction of yolk-shell zinc cobaltite with uniform carbon doping for high performance asymmetric supercapacitor
}

\begin{abstract}
The zinc cobaltite $\left(\mathrm{ZnCo}_{2} \mathrm{O}_{4}\right)$ is a promising material for supercapacitors with appreciable theoretical capacitance. However, it suffers from poor electrical conductivity and large volume expansion during charge-discharge process. In this work a novel material, $\mathrm{ZnCo}_{2} \mathrm{O}_{4} @ \mathrm{C}$ microspheres in a yolk-shell structure is fabricated by a facile refluxing process in combination with a calcination treatment. The carbon is in situ formed via the pyrolysis of organic species and uniformly dispersed both in the core and the shell. Benefiting from the unique structure and the synergistic effect of two components, this material exhibits remarkable electrochemical properties such as high specific capacitance (1821 $\mathrm{F} \mathrm{g}^{-1}$ at $\left.5 \mathrm{~A} \mathrm{~g}^{-1}\right)$, excellent rate performance, superior cycling stability (no capacitance loss over 9000 cycles). The assembled asymmetric supercapacitor coupled with an active carbon anode can deliver a high energy density of $45.9 \mathrm{Wh} \mathrm{kg}^{-1}$ at a power density of $700 \mathrm{~W} \mathrm{~kg}^{-1}$ with an excellent cycling stability (i.e. a capacitance retention rate over $95 \%$ after 9000 cycles).
\end{abstract}

KEYWORDS: $\mathrm{ZnCo}_{2} \mathrm{O}_{4}$; carbon doping; yolk-shell; refluxing; asymmetric supercapacitors

\section{Introduction}

Compared with batteries, supercapacitors possess merits of long lifetime, high power density and fast charge-discharge rate [1-5]. They have attracted significant 
attention in recent years. According to the energy storage mechanism, they can be mainly classified into two types: electrical double-layer capacitor (EDLC) and pseudocapacitor [6, 7]. The pseudocapacitors using transition metal oxides or conducting polymers as electrode materials usually display high specific capacitance but with inferior cycling stability. It is highly desirable to develop new materials with high specific capacitance and long cycle life as well.

The nanostructured ternary transition metal oxides are the promising materials due to their fascinating electrochemical properties including high electrochemical activities and appreciable capacitance [8-10]. Among various ternary transition metal oxides, the $\mathrm{ZnCo}_{2} \mathrm{O}_{4}$ with different structures has demonstrated impressive performance. For example, the mesoporous $\mathrm{ZnCo}_{2} \mathrm{O}_{4}$ solid microspheres could attain a specific capacitance of $953 \mathrm{~F} \mathrm{~g}^{-1}$ at $4 \mathrm{~A} \mathrm{~g}^{-1}$ with a retention rate of $97.8 \%$ after 3000 cycles [11]. The urchin-like $\mathrm{ZnCo}_{2} \mathrm{O}_{4}$ microspheres on nickel foam delivered a specific capacitance of $1143 \mathrm{~F} \mathrm{~g} \mathrm{~g}^{-1}$ at $1.25 \mathrm{~A} \mathrm{~g}^{-1}$ [12]. The incorporation with a second component such as $\mathrm{Ni}(\mathrm{OH})_{2}$ [13]; or even with two components such as $\mathrm{ZnO}$ and multiwall carbon nanotubes [14], reduced graphene oxide and $\mathrm{NiO}$ [15] can even improve the supercapacitive performance. The addition of carbon materials in the composite can effectively increase the conductivity, decrease the volume expansion of nanostructured metal oxides and effectively inhibit the agglomeration of nanoparticles leading to enhanced rate and cycling performance [16-20]. Among all the nanostructures, the yolk-shell structure is regarded as a promising structure affording high storage performance owing to the increased specific area, electroactive sites and short diffusion 
distance $[21,22]$. To the best of our knowledge, the yolk-shell $\mathrm{ZnCo}_{2} \mathrm{O}_{4}$ microspheres with uniform carbon doping has not been reported yet.

Herein, we have successfully developed a novel $\mathrm{ZnCo}_{2} \mathrm{O}_{4}$ composite with the in situ formed and uniformly dispersed carbon $\left(\mathrm{ZnCo}_{2} \mathrm{O}_{4} @ \mathrm{C}\right)$ via a facile refluxing process coupled with a thermal treatment. It is of a yolk-shell structure with porous thin shell which facilitates ion and electron transport; an interspace which acts as a buffer to accommodate the volume changes and in situ formed carbon which not only improves the conductivity but prevents the aggregation of $\mathrm{ZnCo}_{2} \mathrm{O}_{4}$ nanoparticles during charge-discharge process. This material demonstrates an impressive performance: a high capacitance of $1821 \mathrm{~F} \mathrm{~g}^{-1}$ at $5 \mathrm{~A} \mathrm{~g} \mathrm{~g}^{-1}$, outstanding rate performance with the capacitance retention rate of $77.5 \%$ when the current density increases from 2 $\mathrm{A} \mathrm{g}^{-1}$ to $20 \mathrm{~A} \mathrm{~g}^{-1}$ and excellent cycling stability with no capacitance loss over 9000 cycles. The asymmetric supercapacitor coupled with active carbon anode $\left(\mathrm{ZnCo}_{2} \mathrm{O}_{4} @ \mathrm{C} / / \mathrm{AC}\right)$ delivers a high energy density of $45.9 \mathrm{Wh} \mathrm{kg}^{-1}$ at a power density of $700 \mathrm{~W} \mathrm{~kg}^{-1}$ with a superior cycling stability.

\section{Experimental Section}

\subsection{Material Synthesis:}

All the chemicals were of analytical grade and used without further purification. For the synthesis of $\mathrm{ZnCo}_{2} \mathrm{O}_{4} @ \mathrm{C}$ microspheres, a facile refluxing method was conducted followed by a thermal decomposition process. In a typical procedure, $0.15 \mathrm{~g}$ of polyvinyl pyrrolidone (PVP, Mw 58000, Alfa Aesar) was dissolved into $50 \mathrm{~mL}$ of ethylene glycol (EG, Tianjin Fengchuan chemicals) forming a transparent solution; 
followed by the addition of $109.75 \mathrm{mg}$ of $\mathrm{Zn}\left(\mathrm{CH}_{3} \mathrm{COO}\right)_{2} \cdot 2 \mathrm{H}_{2} \mathrm{O}$ (Tianjin Guangfu Fine chemicals) and $249.08 \mathrm{mg}$ of $\mathrm{Co}\left(\mathrm{CH}_{3} \mathrm{COO}\right)_{2} \cdot 4 \mathrm{H}_{2} \mathrm{O}$ (Tianjin Guangfu Fine chemicals). The mixture was continuously stirred for 30 minutes to form a clear purple solution. The obtained solution was transferred into a flask and refluxed at $170{ }^{\circ} \mathrm{C}$ for $2 \mathrm{~h}$. This solution was cooled down to the room temperature naturally. The purple precipitate precursor (ZnCo-glycolate) was collected by centrifugation and rinsed with water and ethanol for several times; followed by a drying process at $80^{\circ} \mathrm{C}$ for $12 \mathrm{~h}$ in a vacuum oven. Then it was annealed at $400{ }^{\circ} \mathrm{C}$ for $4 \mathrm{~h}$ at a heating rate of $1{ }^{\circ} \mathrm{C} \mathrm{min}-1$ under an air atmosphere to form $\mathrm{ZnCo}_{2} \mathrm{O}_{4} @ \mathrm{C}$ microspheres.

\subsection{Material characterization:}

The crystal phases were identified with the X-ray diffraction (XRD, Rigaku MiniFlex II with $\mathrm{Cu}$ Ka radiation). The microstructures were characterized by field emission scanning electron microscopy (FESEM, JEOL JSM-6700F) and transmission electron microscopy (TEM, JEOL JEM-2100). The thermal behavior of the precursor was investigated using thermogravimetric analyzer (TGA, LABSYS EVO) in air. To examine the surface composition and chemical state of the elements, X-ray photoelectron spectroscopy (XPS, PHI 5000 Versa Probe) was carried out. The specific surface area was studied using nitrogen adsorption/desorption measurement on a NOVE 2200e. The porous nature of the samples was estimated using the adsorption curve according to the Barrett-Joyner- Halenda (BJH) model.

\subsection{Electrochemical characterization:}

The working electrode was fabricated by coating a nickel (Ni) foam substrate with 
a slurry composed of active material $\left(\mathrm{ZnCo}_{2} \mathrm{O}_{4} @ \mathrm{C}\right)$, acetylene black and polyvinylidene fluoride (PVDF) binder in a weight ratio of 7:2:1; followed by a drying process at $80^{\circ} \mathrm{C}$ for $12 \mathrm{~h}$ in a vacuum oven. All the electrochemical measurements were performed in a three-electrode configuration in $2 \mathrm{M} \mathrm{KOH}$ electrolyte. A blank Ni foam and $\mathrm{Hg} / \mathrm{HgO}$ electrode were used as counter electrode and reference electrode, respectively. Cyclic voltammetry $(\mathrm{CV})$, chronopotentiometry $(\mathrm{CP})$ and electrochemical impedance spectroscopy (EIS) measurements were conducted with a CHI 660D electrochemical workstation. Galvanostatic charge-discharge (GCD) measurements and cycling performance of the material were evaluated with a LAND battery (Wuhan LAND electronics Co., Ltd.).

The specific capacitance can be calculated from the GD curves according to the equation (1):

$$
C=\frac{I \Delta t}{m \Delta V}
$$

Where $\mathrm{C}\left(\mathrm{F} \mathrm{g} \mathrm{g}^{-1}\right)$ represents the specific capacitance, I (A) is the discharge current, $\Delta t$ (s) is the discharge time, $\mathrm{m}(\mathrm{g})$ for the mass of the active material, and $\Delta V$ represents the potential window.

2.4 Fabrication and evaluation of the asymmetric supercapacitors:

The asymmetric supercapacitors were assembled with $\mathrm{ZnCo}_{2} \mathrm{O}_{4} @ \mathrm{C}$ cathode and active carbon (AC) anode in $2.0 \mathrm{M} \mathrm{KOH}$ electrolyte. The mass ratio of the positive electrode and negative electrode is determined by the following charge balance equation (2):

$$
m^{+} C^{+} \Delta V^{+}=m^{-} C^{-} \Delta V^{-}
$$


$m^{+}$and $m^{-}$are the mass, $C^{+}$and $C^{-}$refer to the specific capacitance, $\Delta V^{+}$ and $\Delta V^{-}$represent the potential window of the positive electrode and negative electrode, respectively.

The specific capacitance of the $\mathrm{ZnCo}_{2} \mathrm{O}_{4} @ \mathrm{C} / / \mathrm{C}$ is calculated based on the total amount of active materials on both electrodes. The energy density and power density of the asymmetric supercapacitors are calculated according to the equation (3) and (4):

$$
E=\frac{C U^{2}}{2 \times 3.6}
$$

Where $\mathrm{E}\left(\mathrm{Wh} \mathrm{kg}^{-1}\right)$ refers to the energy density, $\mathrm{C}(\mathrm{F} \mathrm{g}-1)$ for the specific capacitance calculated from the discharge curve, $\mathrm{U}(\mathrm{V})$ represents the potential window, respectively.

$$
P=\frac{3600 \times E}{\Delta t}
$$

Where $\mathrm{P}\left(\mathrm{W} \mathrm{kg}^{-1}\right)$ refers to the power density, $\mathrm{E}\left(\mathrm{Wh} \mathrm{kg}^{-1}\right)$ for the energy density and $\Delta t(\mathrm{~s})$ is the discharge time.

\section{Results and Discussion}

The formation of the yolk-shell $\mathrm{ZnCo}_{2} \mathrm{O}_{4} @ \mathrm{C}$ microspheres is illustrated in Fig. 1. It starts with the anchoring of $\mathrm{Zn}^{2+}, \mathrm{Co}^{2+}$ on the PVP in the EG solution due to the strong interaction between metal ions and the $\mathrm{C}-\mathrm{N}$ or $\mathrm{C}=\mathrm{O}$ groups of the PVP [23]. With refluxing at $170{ }^{\circ} \mathrm{C}$, the solution turns purplish grey, representing the formation of precursor ZnCo-glycolate (Fig. 1- II ). A thermal analysis was conducted to verify the transform temperature (Fig. S1, Supporting Information). The weight loss below 200 ${ }^{\circ} \mathrm{C}$ is mainly ascribed to the evaporation of adsorbed water. The dominating weigh loss occurred above $250^{\circ} \mathrm{C}$ can be attributed to the thermal decomposition of the precursor 
ZnCo-glycolate into $\mathrm{ZnCo}_{2} \mathrm{O}_{4} @ \mathrm{C}$ [24]. To ensure the complete transformation, we chose $400{ }^{\circ} \mathrm{C}$ as the calcination temperature. After annealing, the organic species including PVP, $\mathrm{CH}_{3} \mathrm{COO}^{-}$and partial EG are decomposed forming the uniformly dispersed carbon in situ. The temperature gradient along the radial direction leads to different decomposition and the shrinking rates, resulting in an interspace between the out shell and the inner core [25]. The $\mathrm{ZnCo}_{2} \mathrm{O}_{4} @ \mathrm{C}$ microspheres with a yolk-shell structure are obtained (Fig. 1-III).

The XRD was used to characterize the crystal phase and the results are shown in Fig. S2. The purple precursor displays a broad diffraction peak at $\sim 11^{\circ}$, which can be assigned to metal glycolates [26, 27]. After the anneal treatment, it exhibits a broad peak at $\sim 23^{\circ}$, corresponding to the amorphous carbon phase; the other peaks can be well assigned to the cubic spinel $\mathrm{ZnCo}_{2} \mathrm{O}_{4}$ phase with a space group of $\mathrm{Fd}-3 \mathrm{~m}$ (JCPDS card no.23-1390). These results clearly demonstrate the formation of $\mathrm{ZnCo}_{2} \mathrm{O}_{4} @ \mathrm{C}$.

The microstructure of the $\mathrm{ZnCo-glycolate}$ and $\mathrm{ZnCo}_{2} \mathrm{O}_{4} @ \mathrm{C}$ was investigated using FESEM and TEM (Fig. 2). The ZnCo-glycolate particles are uniform microspheres that have a diameter of 600 to $800 \mathrm{~nm}$ (Fig. 2a, c) with a solid feature (Fig. 2e). After annealing, these microspheres maintain their original shape and size but in a yolk-shell structure with a clear interspace (Fig. 2b, d). It is also noticed that the microsphere is composed of nanoparticles with a size of $\sim 20 \mathrm{~nm}$. The thickness of the out shell is $\sim 20 \mathrm{~nm}$. Notably, abundant interparticle mesopores with a size of 5-25 nm are formed (Fig. 2f). This result can be further confirmed by the BET analysis (Fig. S3). The $\mathrm{ZnCo}_{2} \mathrm{O}_{4} @ \mathrm{C}$ exhibits clear lattice fringes with an interplane spacing of $4.68 \AA$ and 
$2.43 \AA$ (Fig. 2g), corresponding to the (111) and (311) plane of $\mathrm{ZnCo}_{2} \mathrm{O}_{4}$, respectively. The selective area electron diffraction (SAED) pattern contains several well-defined diffraction rings (Fig. 2h), which can be indexed to the (111), (220), (311), (400), (511) and (440) planes of $\mathrm{ZnCo}_{2} \mathrm{O}_{4}$. These results are in accordance with the XRD characterization.

As illustrated by the TEM image and the relevant elemental mapping in Fig. 3, all the elements $\mathrm{Zn}$, Co and $\mathrm{C}$ are uniformly dispersed, confirming the formation of $\mathrm{ZnCo}_{2} \mathrm{O}_{4} @ \mathrm{C}$ microspheres. Moreover, the carbon element is not only present in the out shell but also in the inner core, further confirming the formation of carbon in situ. Element Analysis (EA) was conducted to estimate the weight percentage of carbon in the $\mathrm{ZnCo}_{2} \mathrm{O}_{4} @ \mathrm{C}$ composite. The result of EA shows the carbon content is 2.9\% wt.. Carbon can improve the electrical conductivity of materials and reduce aggregation between nanoparticles [28-30]. Excellent electrochemical properties may be expected from this material.

In order to have an insight into the chemical composition and obtain more detailed information about the yolk-shell $\mathrm{ZnCo}_{2} \mathrm{O}_{4} @ \mathrm{C}$ microspheres, the XPS measurement was conducted. As expected all the elements $\mathrm{Zn}, \mathrm{Co}, \mathrm{O}$ and $\mathrm{C}$ are found (Fig. 4). The Zn 2p spectrum contains two major peaks at $1020.9 \mathrm{eV}$ and $1044.0 \mathrm{eV}$ (Fig. 4a) in accordance with the $\mathrm{Zn} 2 \mathrm{p}_{3 / 2}$ and $\mathrm{Zn} 2 \mathrm{p}_{1 / 2}$, clearly demonstrating the existence of $\mathrm{Zn}$ (II) ions $[19,31]$. The Co $2 p$ spectrum in Fig. $4 \mathrm{~b}$ is composed of two spin-orbit doublets with two shake up satellites (named as "Sat."), which can be respectively attributed to the Co (II) peaks at $780.5 \mathrm{eV}$ and $796.2 \mathrm{eV}$, and $\mathrm{Co}$ (III) peaks at $779.9 \mathrm{eV}$ and 794.8 
$\mathrm{eV}[10,32]$. The XPS spectrum of $\mathrm{O} 1 \mathrm{~s}$ can be divided into two photoelectron peaks at $529.7 \mathrm{eV}$ and $531.2 \mathrm{eV}$, and denoted as $\mathrm{O} 1$ and $\mathrm{O} 2$ (Fig. 4c). The $\mathrm{O} 1$ peak suggests the typical metal-oxygen bonds, and the $\mathrm{O} 2$ peak reveals the defect sites lacking of oxygen coordination [32]. The $\mathrm{C} 1 \mathrm{~s}$ curve can be split into three peaks at $284.8 \mathrm{eV}, 286.4 \mathrm{eV}$ and $288.8 \mathrm{eV}$, which can be respectively assigned to the $\mathrm{C}-\mathrm{C}$ bonds, $\mathrm{C}=\mathrm{O}$ bonds, and O-C-O groups (Fig. 4d) [19].

The electrochemical properties of the yolk-shell $\mathrm{ZnCo}_{2} \mathrm{O}_{4} @ \mathrm{C}$ microspheres as a supercapacitor electrode were investigated in $2 \mathrm{M} \mathrm{KOH}$. The contribution from the $\mathrm{Ni}$ foam substrate is negligible as evidenced by its very low current response over the applied potential window of 0-0.6 V compared to the $\mathrm{ZnCo}_{2} \mathrm{O}_{4} @ \mathrm{C}$ electrode (Fig. 5a). The $\mathrm{ZnCo}_{2} \mathrm{O}_{4} @ \mathrm{C}$ exhibits a pair of strong redox peaks at a scan rate range of 1 to 50 $\mathrm{mV} \mathrm{s}^{-1}$ (Fig. 5b). The anodic peak at $0.51 \mathrm{~V}$ and cathodic peak at $0.33 \mathrm{~V}$ correspond to the oxidation of $\mathrm{CoOOH}$ to $\mathrm{CoO}_{2}$, as illustrated in the following equations [33, 34]:

$$
\begin{gathered}
\mathrm{ZnCo}_{2} \mathrm{O}_{4}+2 \mathrm{H}_{2} \mathrm{O}+2 \mathrm{OH}^{-} \rightarrow \mathrm{Zn}(\mathrm{OH})_{4}{ }^{2-}+2 \mathrm{CoOOH} \\
\mathrm{CoOOH}+\mathrm{OH}^{-} \leftrightarrow \mathrm{CoO}_{2}+\mathrm{H}_{2} \mathrm{O}+e^{-}
\end{gathered}
$$

The anodic peak shifts towards positive potential while the cathodic peak shifts towards negative potential with the increase of the scan rate. It is common for pseudocapacitor materials, which can be ascribed to the slow diffusion rate of ions that can not satisfy the electrochemical reaction rate. The presence of clear and pronounced redox peaks at a high scan rate of $50 \mathrm{mV} \mathrm{s}^{-1}$ is indicative of fast redox reactions and good reversibility of $\mathrm{ZnCo}_{2} \mathrm{O}_{4} @ \mathrm{C}$. This material also displays a good linear relationship between the anodic peak current and the square root of the scan rate (Fig. 
5c). Such behavior generally implies a diffusion-controlled reaction for the redox reaction [35].

To further evaluate the capacitive behavior, the EIS was carried out. The impedance spectrum is composed of a semicircle and a nearly vertical line (Fig. 5d). The intercept on the real axis in high frequency region represents the bulk resistance $\left(R_{s}\right)$, which contains the inherent resistance of active material, electrolyte as well as the contact resistance between current collector and active material. It is very small and only $0.4 \mathrm{ohm}$, indicating the good electrical conductivity of this electrode. The semicircle reflects the charge transfer resistance $\left(\mathrm{R}_{\mathrm{ct}}\right)$ during redox reactions [13]. The smaller the radius of semicircle is, the easier the charge transfers. The very sharp slope of the $\mathrm{ZnCo}_{2} \mathrm{O}_{4} @ \mathrm{C}$ observed in low frequency region suggests low Warburg impedance $\left(\mathrm{W}_{\mathrm{o}}\right)$. It means that ions in the electrolyte are easier to diffuse to the electrode surface achieving a good rate performance $[36,37]$. The $\mathrm{R}_{\mathrm{ct}}$ and $\mathrm{W}_{\mathrm{o}}$ are $0.1 \mathrm{ohm}$ and $1.5 \mathrm{ohm}$, respectively, which are smaller than previously reported similar material for supercapacitors (Table S1). Such extraordinary small resistances are ascribed to the in situ formed and uniformly dispersed carbon, indicating the high electrochemical activity.

To estimate the specific capacitance of the $\mathrm{ZnCo}_{2} \mathrm{O}_{4} @ \mathrm{C}$, galvanostatic chargedischarge measurements were employed over a potential window of 0.1 to $0.6 \mathrm{~V}$. Fig. 6a presents the discharge curves at a series of current densities. It delivers a superior specific capacitance at the applied current densities of 2 to $20 \mathrm{~A} \mathrm{~g}^{-1}$ : a specific capacitance of $2064 \mathrm{~F} \mathrm{~g} \mathrm{~g}^{-1}$ at $2 \mathrm{~A} \mathrm{~g} \mathrm{~g}^{-1}$; and $1600 \mathrm{~F} \mathrm{~g}^{-1}$ at $20 \mathrm{~A} \mathrm{~g}^{-1}$ with a $77.5 \%$ of 
capacitance retention (Table S2, Fig. 6b). The rate performance was also conducted after 6000 cycles (Fig. 6c). The specific capacitance is $1674,1431,1281$ and $1201 \mathrm{~F} \mathrm{~g}^{-}$ ${ }^{1}$ at a current density of $2,5,10$ and $20 \mathrm{~A} \mathrm{~g}^{-1}$, respectively. When the current density reverses to $2 \mathrm{~A} \mathrm{~g} \mathrm{~g}^{-1}$, the specific capacitance is fully restored with a slight increase to $1751 \mathrm{~F} \mathrm{~g}^{-1}$, clearly demonstrating the superior reversibility of this material.

Lifetime is an important parameter to evaluate the performance of a supercapacitor. The cycling performance of $\mathrm{ZnCo}_{2} \mathrm{O}_{4} @ \mathrm{C}$ was conducted at $5 \mathrm{~A} \mathrm{~g}^{-1}$ (Fig. 6d). It exhibits an exceptional cycling performance without any capacitance loss over 9000 chargedischarge cycles but slightly increases instead. Based on some previous reports [38-40], the major reason of constant gain in capacitance of the materials can be mainly ascribe to the wettability of the active materials and electrochemical active process. With the increasing of cycling numbers, the electrolyte ions penetrated deeply into the active materials, enhancing the reversible redox reaction. In summary, the electrochemical performance of $\mathrm{ZnCo}_{2} \mathrm{O}_{4} @ \mathrm{C}$ is far superior to the previously reported $\mathrm{ZnCo}_{2} \mathrm{O}_{4}$ materials for supercapacitors (Table S3).

Such attractive electrochemical performances can be ascribed to its unique structural merits: a permeable thin shell, an interspace between the core and the shell and the finely dispersed and highly uniformed carbon. The shell consists of vast small nanoparticles and possesses abundant mesopores, which affords a short pathway for ion and electron transport [41]. The interspace can store electrolyte and serve as a reservoir of ions, which greatly enhances the diffusion kinetics. Moreover, the interspace not only provides a buffer to relieve the volume expansion during cycling process, but also 
offers more electroactive sites for redox reactions, contributing to the total specific capacitance [42]. The inner core which can move freely gives a mechanical support to the outer shell [43]. The in situ formed carbon not only increases the conductivity but also restrains the aggregation of $\mathrm{ZnCo}_{2} \mathrm{O}_{4}$ nanoparticles [28- 30].

To increase the electrochemical window of the supercapacitor, an asymmetric supercapacitor was fabricated by using the $\mathrm{ZnCo}_{2} \mathrm{O}_{4} @ \mathrm{C}$ as cathode coupled with an active carbon anode. As discussed above, the $\mathrm{ZnCo}_{2} \mathrm{O}_{4} @ \mathrm{C}$ demonstrates a suitable potential window over the range of 0 to $0.6 \mathrm{~V}$; and the active carbon is stable over a potential window of -0.9 to $0 \mathrm{~V}$ (Fig. 7a). Thus the potential window for the $\mathrm{ZnCo}_{2} \mathrm{O}_{4} @ \mathrm{C} / / \mathrm{AC}$ asymmetric supercapacitor can be extended to $1.5 \mathrm{~V}$ in theory. The $\mathrm{CV}$ measurements were carried out from 0.0 to $1.5 \mathrm{~V}$ at a scan rate of $5 \mathrm{mV} \mathrm{s}^{-1}$ to confirm an approximate electrochemical window. When the working voltage reachs 1.5 $\mathrm{V}$, the electrolyte is slowly decomposed as demonstrated by the appearance of obvious oxygen evolution (Fig. 7b). Therefore, a potential window of 0 to $1.4 \mathrm{~V}$ is chosen for the $\mathrm{ZnCo}_{2} \mathrm{O}_{4} @ \mathrm{C} / / \mathrm{AC}$. The current response exhibits a similar shape at a scan rate range of 1 to $20 \mathrm{mV} \mathrm{s}^{-1}$ (Fig. 7c), demonstrating a good rate performance. The CP tests were performed at a serious of current densities (Fig. 7d) and the corresponding specific capacitance shows in Fig. 7e. It delivers a specific capacitance of 169, 163, 143 and 93 $\mathrm{F} \mathrm{g}^{-1}$ at $1,2,5$ and $10 \mathrm{~A} \mathrm{~g}^{-1}$, respectively. It also displays an extraordinary cycling stability with a capacitance retention rate over $95 \%$ over 9000 cycles at a current density of $1 \mathrm{~A} \mathrm{~g}^{-1}$ (Fig 7f). The charge-discharge curves of the last 12 cycles during these 9000 cycles are nearly identical to each other, which is indicative of an excellent 
electrochemical reversibility.

The energy density and the power density are two important factors for the evaluation of the asymmetric supercapacitor. This $\mathrm{ZnCo}_{2} \mathrm{O}_{4} @ \mathrm{C} / / \mathrm{AC}$ asymmetric supercapacitor delivers a high energy density of $45.9 \mathrm{Wh} \mathrm{kg}^{-1}$ at a power density of 700 $\mathrm{W} \mathrm{kg}$; and it can still present a high energy density of $25.3 \mathrm{Wh} \mathrm{kg}^{-1}$ at a high power density of $7 \mathrm{~kW} \mathrm{~kg}^{-1}$. These results are better than the previously reported zinc-cobaltbased supercapacitors such as $\mathrm{ZnCo}_{2} \mathrm{O}_{4} / \mathrm{NGN} / \mathrm{CNT} / \mathrm{NGN} / \mathrm{CNT}\left(37.2 \mathrm{Wh} \mathrm{kg}^{-1}\right.$ at 750 $\left.\mathrm{W} \mathrm{kg}^{-1}\right)$ [44] and $\mathrm{ZnCo}_{2} \mathrm{O}_{4} @ \mathrm{NiX}_{\mathrm{X}} \mathrm{Co}_{2 \mathrm{X}}(\mathrm{OH})_{6 \mathrm{X}} / / \mathrm{AC}\left(26.2 \mathrm{Wh} \mathrm{kg}^{-1}\right.$ at $\left.511.8 \mathrm{~W} \mathrm{~kg}^{-1}\right)(\mathrm{Fig}$. 8) [45].

\section{Conclusions}

In summary, $\mathrm{ZnCo}_{2} \mathrm{O}_{4} @ \mathrm{C}$ microspheres have successfully developed with uniform carbon doping in situ via a facile refluxing process coupled with a calcination treatment. It is of a yolk-shell structure with porous thin shell which can facilitate ion and electron transport; the interspace acted as a buffer which can accommodate the volume expansion; the in situ formed and finely dispersed carbon both in the core and the shell via the pyrolysis of organic species can improve the conductivity and prevent $\mathrm{ZnCo}_{2} \mathrm{O}_{4}$ nanoparticles aggregation. The method applied in this work is readily to synthesize other carbon-metal oxides as high performance materials for energy storage. The $\mathrm{ZnCo}_{2} \mathrm{O}_{4} @ \mathrm{C}$ exhibits excellent electrochemical properties including high specific capacitance, excellent rate performance and superior cycling performance. The combination of the outstanding electrochemical properties and the facile and straightforward fabrication method makes $\mathrm{ZnCo}_{2} \mathrm{O}_{4} @ \mathrm{C}$ a promising material for 
supercapacitors.

\section{Supporting Information}

Supporting Information can be found in the online version.

\section{Acknowledgements}

This work was financially supported by MOST (2016YFA0202500), 111 Project (B12015), NSFC (51471089, 51501072) and NSFT (17JCYBJC17900).

\section{References}

[1] G. Wang, L. Zhang, J. Zhang, A review of electrode materials for electrochemical supercapacitors, Chem. Soc. Rev. 41 (2012) 797-828.

[2] S. Li, L.-L. Yu, R.-B. Li, J. Fan, J.-T. Zhao, Template-free and room-temperature synthesis of $3 \mathrm{D}$ sponge-like mesoporous $\mathrm{Mn}_{3} \mathrm{O}_{4}$ with high capacitive performance, Energy Storage Mater. (2017).

[3] P. Zhang, B.Y. Guan, L. Yu, X.W. Lou, Formation of Double-Shelled Zinc-Cobalt Sulfide Dodecahedral Cages from Bimetallic Zeolitic Imidazolate Frameworks for Hybrid Supercapacitors, Angew. Chem. Int. Ed. 56 (2017) 7141-7145.

[4] P. Simon, Y. Gogotsi, Materials for electrochemical capacitors, Nat. Mater. 7 (2008) 845-854.

[5] J.-G. Wang, R. Zhou, D. Jin, K. Xie, B. Wei, Controlled synthesis of $\mathrm{NiCo}_{2} \mathrm{~S}_{4}$ nanostructures on nickel foams for high-performance supercapacitors, Energy Storage Mater. 2 (2016) 1-7.

[6] P. Yang, P. Sun, W. Mai, Electrochromic energy storage devices, Mater. Today 19 
(2016) 394-402.

[7] L.L. Zhang, X.S. Zhao, Carbon-based materials as supercapacitor electrodes, Chem. Soc. Rev. 38 (2009) 2520-2531.

[8] L.F. Shen, L. Yu, X.Y. Yu, X.G. Zhang, X.W. Lou, Self-Templated Formation of Uniform $\mathrm{NiCo}_{2} \mathrm{O}_{4}$ Hollow Spheres with Complex Interior Structures for Lithium-Ion Batteries and Supercapacitors, Angew. Chem. Int. Ed. 54 (2015) 1868-1872.

[9] B.Y. Guan, A. Kushima, L. Yu, S. Li, J. Li, X.W. Lou, Coordination Polymers Derived General Synthesis of Multishelled Mixed Metal-Oxide Particles for Hybrid Supercapacitors, Adv. Mater. 29 (2017) 1605902-n/a.

[10] Y. Zhang, B. Wang, F. Liu, J. Cheng, X.-w. Zhang, L. Zhang, Full synergistic contribution of electrodeposited three-dimensional $\mathrm{NiCo}_{2} \mathrm{O}_{4} @ \mathrm{MnO}_{2}$ nanosheet networks electrode for asymmetric supercapacitors, Nano Energy 27 (2016) 627-637. [11] Q. Wang, J. Du, Y. Zhu, J. Yang, J. Chen, C. Wang, L. Li, L. Jiao, Facile fabrication and supercapacitive properties of mesoporous zinc cobaltite microspheres, J. Power Sources 284 (2015) 138-145.

[12] H.S. Jadhav, A. Roy, W.-J. Chung, J.G. Seo, Growth of urchin-like $\mathrm{ZnCo}_{2} \mathrm{O}_{4}$ microspheres on nickel foam as a binder-free electrode for high-performance supercapacitor and methanol electro-oxidation, Electrochimica Acta 246 (2017) 941950.

[13] H.X. Chuo, H. Gao, Q. Yang, N. Zhang, W.B. Bu, X.T. Zhang, Rationally designed hierarchical $\mathrm{ZnCo}_{2} \mathrm{O}_{4} / \mathrm{Ni}(\mathrm{OH})_{2}$ nanostructures for high-performance pseudocapacitor electrodes, J. Mater. Chem. A 2 (2014) 20462-20469. 
[14] J. Sun, P. Zan, L. Ye, X. Yang, L. Zhao, Superior performance of $\mathrm{ZnCo}_{2} \mathrm{O}_{4} / \mathrm{ZnO} @$ multiwall carbon nanotubes with laminated shape assembled as highly practical all-solid-state asymmetric supercapacitors, J. Mater. Chem. A 5 (2017) 98159823.

[15] S. Sahoo, J.-J. Shim, Facile Synthesis of Three-Dimensional Ternary $\mathrm{ZnCo}_{2} \mathrm{O}_{4} /$ Reduced Graphene Oxide/NiO Composite Film on Nickel Foam for Next Generation Supercapacitor Electrodes, ACS Sustainable Chem. Eng. 5 (2017) 241-251.

[16] A.L.M. Reddy, M.M. Shaijumon, S.R. Gowda, P.M. Ajayan, Coaxial $\mathrm{MnO}_{2} /$ Carbon Nanotube Array Electrodes for High-Performance Lithium Batteries, Nano Lett. 9 (2009) 1002-1006.

[17] D. Gu, W. Li, F. Wang, H. Bongard, B. Spliethoff, W. Schmidt, C. Weidenthaler, Y. Xia, D. Zhao, F. Schueth, Controllable Synthesis of Mesoporous Peapod-like $\mathrm{Co}_{3} \mathrm{O}_{4} @$ Carbon Nanotube Arrays for High-Performance Lithium-Ion Batteries, Angew. Chem. Int. Ed. 54 (2015) 7060-7064.

[18] S. Ortaboy, J.P. Alper, F. Rossi, G. Bertoni, G. Salviati, C. Carraro, R. Maboudian, $\mathrm{MnO}_{\mathrm{x}}$-decorated carbonized porous silicon nanowire electrodes for high performance supercapacitors, Energy Environ. Sci. 10 (2017) 1505-1516.

[19] H. Chen, G. Jiang, W. Yu, D. Liu, Y. Liu, L. Li, Q. Huang, Z. Tong, Electrospun carbon nanofibers coated with urchin-like $\mathrm{ZnCo}_{2} \mathrm{O}_{4}$ nanosheets as a flexible electrode material, J. Mater. Chem. A 4 (2016) 5958-5964.

[20] Q. Li, C. Lu, C. Chen, L. Xie, Y. Liu, Y. Li, Q. Kong, H. Wang, Layered $\mathrm{NiCo}_{2} \mathrm{O}_{4} /$ reduced graphene oxide composite as an advanced electrode for 
supercapacitor, Energy Storage Mater. 8 (2017) 59-67.

[21] H. Geng, J. Yang, Z. Dai, Y. Zhang, Y. Zheng, H. Yu, H. Wang, Z. Luo, Y. Guo, Y. Zhang, H. Fan, X. Wu, J. Zheng, Y. Yang, Q. Yan, H. Gu, Cog $\mathrm{S}_{8} / \mathrm{MoS}_{2}$ Yolk-Shell Spheres for Advanced Li/Na Storage, Small 13 (2017).

[22] Y. Wu, J. Meng, Q. Li, C. Niu, X. Wang, W. Yang, W. Li, L. Mai, Interfacemodulated fabrication of hierarchical yolk-shell $\mathrm{Co}_{3} \mathrm{O}_{4} / \mathrm{C}$ dodecahedrons as stable anodes for lithium and sodium storage, Nano Res. 10 (2017) 2364-2376.

[23] G. Zhang, L. Yu, H.B. Wu, H.E. Hoster, X.W. Lou, Formation of $\mathrm{ZnMn}_{2} \mathrm{O}_{4}$ ballin-ball hollow microspheres as a high-performance anode for lithium-ion batteries, Adv. Mater. 24 (2012) 4609-4613.

[24] J. Li, J. Wang, D. Wexler, D. Shi, J. Liang, H. Liu, S. Xiong, Y. Qian, Simple synthesis of yolk-shelled $\mathrm{ZnCo}_{2} \mathrm{O}_{4}$ microspheres towards enhancing the electrochemical performance of lithium-ion batteries in conjunction with a sodium carboxymethyl cellulose binder, J. Mater. Chem. A 1 (2013) 15292-15299.

[25] L. Huang, G.H. Waller, Y. Ding, D. Chen, D. Ding, P. Xi, Z.L. Wang, M. Liu, Controllable interior structure of $\mathrm{ZnCo}_{2} \mathrm{O}_{4}$ microspheres for high-performance lithiumion batteries, Nano Energy 11 (2015) 64-70.

[26] X. Zhou, B.Q. Wang, H.B. Sun, C. Wang, P. Sun, X.W. Li, X.L. Hu, G.Y. Lu, Template-free synthesis of hierarchical $\mathrm{ZnFe}_{2} \mathrm{O}_{4}$ yolk-shell microspheres for highsensitivity acetone sensors, Nanoscale 8 (2016) 5446-5453.

[27] X. Wang, X.-L. Wu, Y.-G. Guo, Y. Zhong, X. Cao, Y. Ma, J. Yao, Synthesis and Lithium Storage Properties of $\mathrm{Co}_{3} \mathrm{O}_{4}$ Nanosheet-Assembled Multishelled Hollow 
Spheres, Adv. Funct. Mater. 20 (2010) 1680-1686.

[28] Y.C. Liu, N. Zhang, L.F. Jiao, J. Chen, Tin Nanodots Encapsulated in Porous Nitrogen-Doped Carbon Nanofibers as a Free-Standing Anode for Advanced SodiumIon Batteries, Adv. Mater. 27 (2015) 6702-6707.

[29] T. Jin, Y. Liu, Y. Li, K. Cao, X. Wang, L. Jiao, Electrospun NaVPO 4 F/C Nanofibers as Self-Standing Cathode Material for Ultralong Cycle Life Na-Ion Batteries, Adv. Energy Mater. (2017) 1700087.

[30] Y. Li, C. Chen, M. Wang, W. Li, Y. Wang, L. Jiao, H. Yuan, Excellent sodium storage performance of carbon-coated $\mathrm{TiO}_{2}$ : Assisted with electrostatic interaction of surfactants, J. Power Sources 361 (2017) 326-333.

[31] J. Cheng, Y. Lu, K. Qiu, H. Yan, X. Hou, J. Xu, L. Han, X. Liu, J.-K. Kim, Y. Luo, Mesoporous $\mathrm{ZnCo}_{2} \mathrm{O}_{4}$ nanoflakes grown on nickel foam as electrodes for high performance supercapacitors, Phys. Chem. Chem. Phys. 17 (2015) 17016-17022.

[32] Y. Huang, Y.-E. Miao, H. Lu, T. Liu, Hierarchical $\mathrm{ZnCo}_{2} \mathrm{O}_{4} @ \mathrm{NiCo}_{2} \mathrm{O}_{4}$ CoreSheath Nanowires: Bifunctionality towards High-Performance Supercapacitors and the Oxygen-Reduction Reaction, Chem. Eur. J. 21 (2015) 10100-10108.

[33] C. Lin, J.A. Ritter, B.N. Popov, Characterization of Sol-Gel-Derived Cobalt Oxide Xerogels as Electrochemical Capacitors, J. Electrochem. Soc. 145 (1998) 4097-4103. [34] F. Zhang, C. Yuan, X. Lu, L. Zhang, Q. Che, X. Zhang, Facile growth of mesoporous $\mathrm{Co}_{3} \mathrm{O}_{4}$ nanowire arrays on $\mathrm{Ni}$ foam for high performance electrochemical capacitors, J. Power Sources 203 (2012) 250-256.

[35] Z.A. Hu, Y.L. Xie, Y.X. Wang, L.J. Xie, G.R. Fu, X.Q. Jin, Z.Y. Zhang, Y.Y. Yang, 
H.Y. Wu, Synthesis of alpha-Cobalt Hydroxides with Different Intercalated Anions and Effects of Intercalated Anions on Their Morphology, Basal Plane Spacing, and Capacitive Property, J. Phys. Chem. C 113 (2009) 12502-12508.

[36] S. Sun, S. Wang, S. Li, Y. Li, Y. Zhang, J. Chen, Z. Zhang, S. Fang, P. Wang, Asymmetric supercapacitors based on a $\mathrm{NiCo}_{2} \mathrm{O}_{4} /$ three dimensional graphene composite and three dimensional graphene with high energy density, J. Mater. Chem. A 4 (2016) 18646-18653.

[37] C. Zheng, C. Cao, R. Chang, J. Hou, H. Zhai, Hierarchical mesoporous $\mathrm{NiCo}_{2} \mathrm{O}_{4}$ hollow nanocubes for supercapacitors, Phys. Chem. Chem. Phys. 18 (2016) 6268-6274. [38] Z. Ye, F. Wang, C. Jia, K. Mu, M. Yu, Y. Lv, Z. Shao, Nitrogen and oxygen-codoped carbon nanospheres for excellent specific capacitance and cyclic stability supercapacitor electrodes, Chem. Eng. J. 330 (2017) 1166-1173.

[39] L. Kong, Q. Chen, X. Shen, C. Xia, Z. Ji, J. Zhu, Ionic Liquid Templated Porous Boron-Doped Graphitic Carbon Nitride Nanosheet Electrode for High-Performance Supercapacitor, Electrochimica Acta 245 (2017) 249-258.

[40] Y. Xu, X. Wang, C. An, Y. Wang, L. Jiao, H. Yuan, Facile synthesis route of porous $\mathrm{MnCo}_{2} \mathrm{O}_{4}$ and $\mathrm{CoMn}_{2} \mathrm{O}_{4}$ nanowires and their excellent electrochemical properties in supercapacitors, J. Mater. Chem. A 2 (2014) 16480-16488.

[41] J. Wang, Q. Zhang, X. Li, D. Xu, Z. Wang, H. Guo, K. Zhang, Three-dimensional hierarchical $\mathrm{Co}_{3} \mathrm{O}_{4} / \mathrm{CuO}$ nanowire heterostructure arrays on nickel foam for highperformance lithium ion batteries, Nano Energy 6 (2014) 19-26.

[42] L. Yu, B. Guan, W. Xiao, X.W. Lou, Formation of Yolk-Shelled Ni-Co Mixed 
Oxide Nanoprisms with Enhanced Electrochemical Performance for Hybrid Supercapacitors and Lithium Ion Batteries, Adv. Energy Mater. 5 (2015).

[43] T. Zhu, J. Wang, G.W. Ho, Self-supported yolk-shell nanocolloids towards high capacitance and excellent cycling performance, Nano Energy 18 (2015) 273-282.

[44] W. Bai, H. Tong, Z. Gao, S. Yue, S. Xing, S. Dong, L. Shen, J. He, X. Zhang, Y. Liang, Preparation of $\mathrm{ZnCo}_{2} \mathrm{O}_{4}$ nanoflowers on a 3D carbon nanotube/nitrogen-doped graphene film and its electrochemical capacitance, J. Mater. Chem. A 3 (2015) 2189121898.

[45] W. Fu, Y. Wang, W. Han, Z. Zhang, H. Zha, E. Xie, Construction of hierarchical $\mathrm{ZnCo}_{2} \mathrm{O}_{4} @ \mathrm{Ni}_{\mathrm{x}} \mathrm{Co}_{2 \mathrm{x}}(\mathrm{OH})_{6 \mathrm{x}}$ core/shell nanowire arrays for high-performance supercapacitors, J. Mater. Chem. A 4 (2016) 173-182.

[46] B. Guan, D. Guo, L. Hu, G. Zhang, T. Fu, W. Ren, J. Li, Q. Li, Facile synthesis of $\mathrm{ZnCo}_{2} \mathrm{O}_{4}$ nanowire cluster arrays on $\mathrm{Ni}$ foam for high-performance asymmetric supercapacitors, J. Mater. Chem. A 2 (2014) 16116-16123.

[47] W. Ma, H. Nan, Z. Gu, B. Geng, X. Zhang, Superior performance asymmetric supercapacitors based on $\mathrm{ZnCo}_{2} \mathrm{O}_{4} @ \mathrm{MnO}_{2}$ core-shell electrode, J. Mater. Chem. A 3 (2015) 5442-5448.

[48] J.A. Rajesh, B.K. Min, J.H. Kim, H. Kim, K.S. Ahn, Cubic Spinel $\mathrm{AB}_{(2)} \mathrm{O}_{(4)}$ Type Porous $\mathrm{ZnCo}_{2} \mathrm{O}_{4}$ Microspheres: Facile Hydrothermal Synthesis and Their Electrochemical Performances in Pseudocapacitor, J. Electrochem. Soc. 163 (2016) A2418-A2427. 


\section{Figure Captions}

\section{Fig. 1 Schematic illustration of the formation of $\mathrm{ZnCo}_{2} \mathrm{O}_{4} @ \mathrm{C}$.}

Fig. 2 FESEM images (a-d) and TEM images (e-g) of ZnCo-glycolate precursor (a, c, e) and $\mathrm{ZnCo}_{2} \mathrm{O}_{4} @ \mathrm{C}(\mathrm{d}, \mathrm{f}, \mathrm{g})$; SAED pattern (h) of $\mathrm{ZnCo}_{2} \mathrm{O}_{4} @ \mathrm{C}$.

Fig. 3 TEM image and the relevant elemental mapping of $\mathrm{ZnCo}_{2} \mathrm{O}_{4} @ \mathrm{C}$.

Fig. 4 XPS spectrums of Zn 2p (a), Co 2p (b), O 1s (c), C 1s (d) of $\mathrm{ZnCo}_{2} \mathrm{O}_{4} @ \mathrm{C}$.

Fig. 5 Cyclic voltammograms $(\mathrm{a}, \mathrm{b})$ of the $\mathrm{ZnCo}_{2} \mathrm{O}_{4} @ \mathrm{C}$ electrode at a scan rate of 10 $\mathrm{mV} \mathrm{s}^{-1}$ with blank Ni foam as control (a), and at different scan rates (b); the relationship between the anodic peak current and the square root of the scan rate (c); EIS spectrum of the $\mathrm{ZnCo}_{2} \mathrm{O}_{4} @ \mathrm{C}$ electrode (d) (Inset, expanded view and the equivalent circuit).

Fig. 6 Galvanostatic discharge curves (a), specific capacitance (b) and rate performance (c) at various current densities of $\mathrm{ZnCo}_{2} \mathrm{O}_{4} @ \mathrm{C}$ electrode in $2 \mathrm{M} \mathrm{KOH}$; Cycling performance of $\mathrm{ZnCo}_{2} \mathrm{O}_{4} @ \mathrm{C}$ electrode at $5 \mathrm{~A} \mathrm{~g}^{-1}$ (d).

Fig. 7 Cyclic voltammograms (a-c) of the active carbon and $\mathrm{ZnCo}_{2} \mathrm{O}_{4} @ \mathrm{C}$ electrode(a), the $\mathrm{ZnCo}_{2} \mathrm{O}_{4} @ \mathrm{C} / / \mathrm{AC}$ asymmetric supercapacitor over different potential windows at a scan rate of $5 \mathrm{mV} \mathrm{s}^{-1}(\mathrm{~b})$, the $\mathrm{ZnCo}_{2} \mathrm{O}_{4} @ \mathrm{C} / / \mathrm{AC}$ asymmetric supercapacitor over a potential window of 0 to $1.4 \mathrm{~V}$ at different scan rates (c); Charge-discharge curves (d), the corresponding specific capacitance at different current densities (e), and the cycling performance at $1 \mathrm{~A} \mathrm{~g}^{-1}$ (f) of the $\mathrm{ZnCo}_{2} \mathrm{O}_{4} @ \mathrm{C} / / \mathrm{AC}$ asymmetric supercapacitor (Inset, the last 12 charge-discharge cycles).

Fig. 8 Ragone plot of the $\mathrm{ZnCo}_{2} \mathrm{O}_{4} / / \mathrm{AC}$ asymmetric supercapacitor in comparison with the previously reported zinc cobaltite-based supercapacitors. 


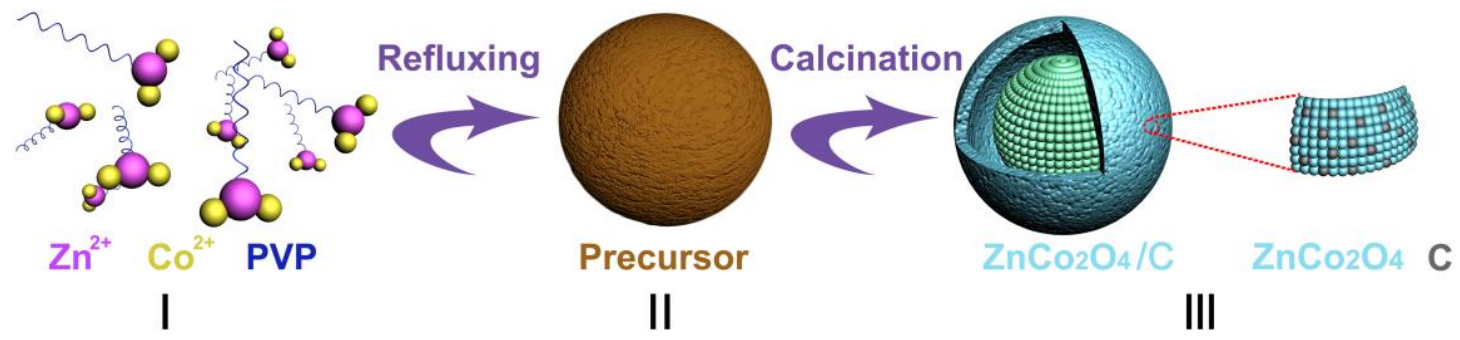

Fig. 1 Schematic illustration of the formation of $\mathrm{ZnCo}_{2} \mathrm{O}_{4} @ \mathrm{C}$. 

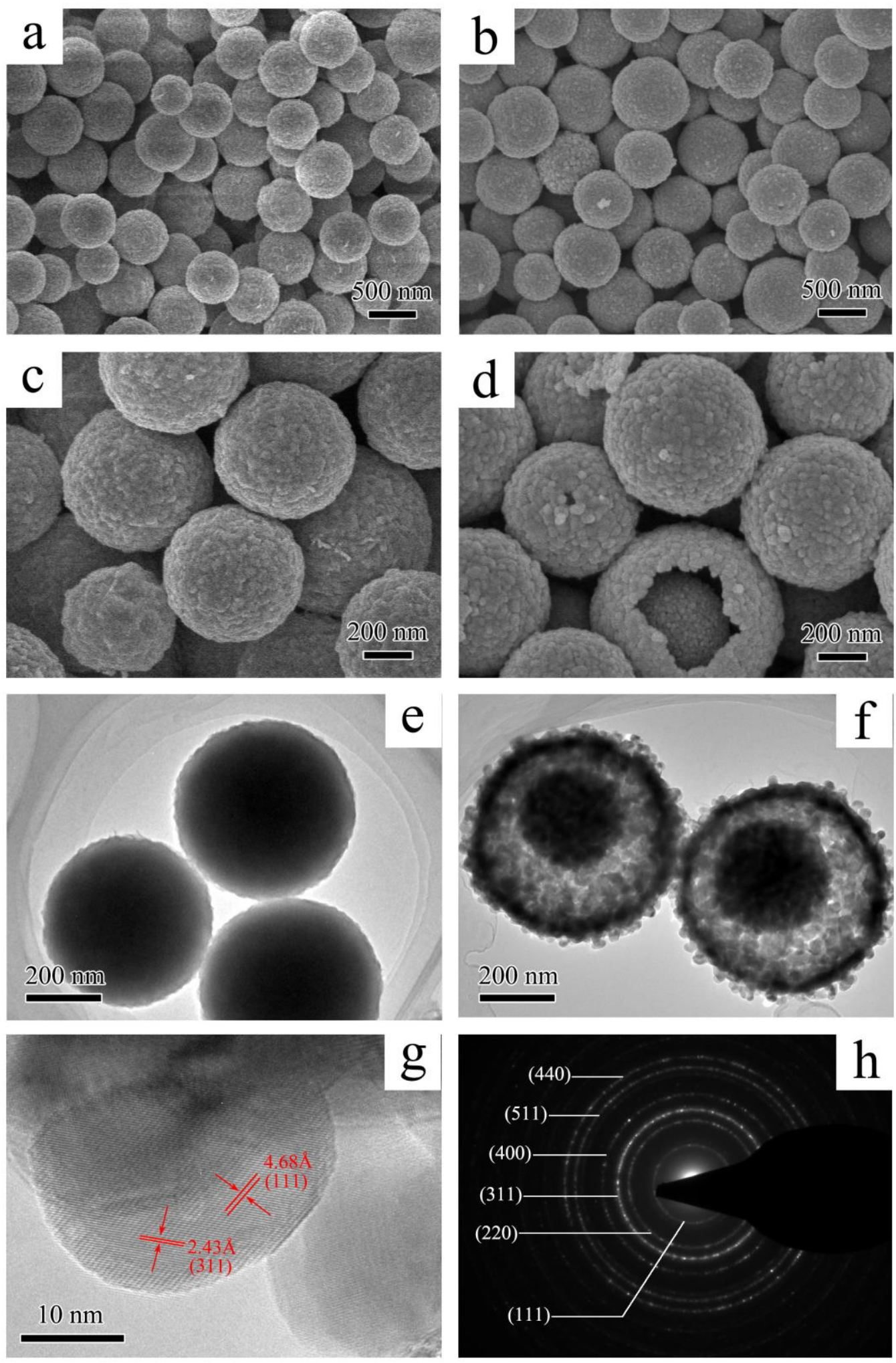

Fig. 2 FESEM images (a-d) and TEM images (e-g) of ZnCo-glycolate precursor (a, c,

e) and $\mathrm{ZnCo}_{2} \mathrm{O}_{4} @ \mathrm{C}(\mathrm{d}, \mathrm{f}, \mathrm{g})$; SAED pattern (h) of $\mathrm{ZnCo}_{2} \mathrm{O}_{4} @ \mathrm{C}$. 

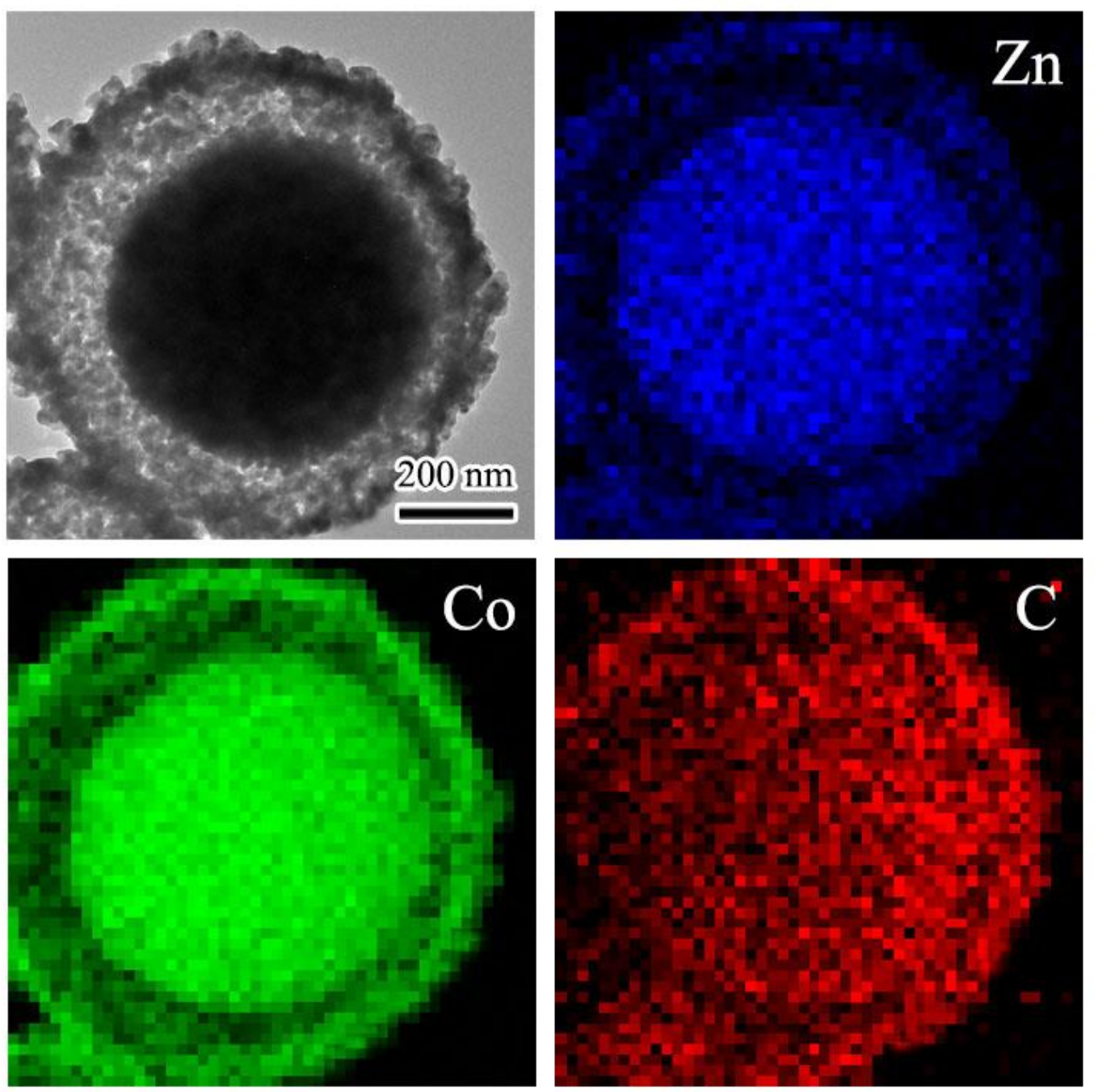

Fig. 3 TEM image and the relevant elemental mapping of $\mathrm{ZnCo}_{2} \mathrm{O}_{4} @ \mathrm{C}$. 

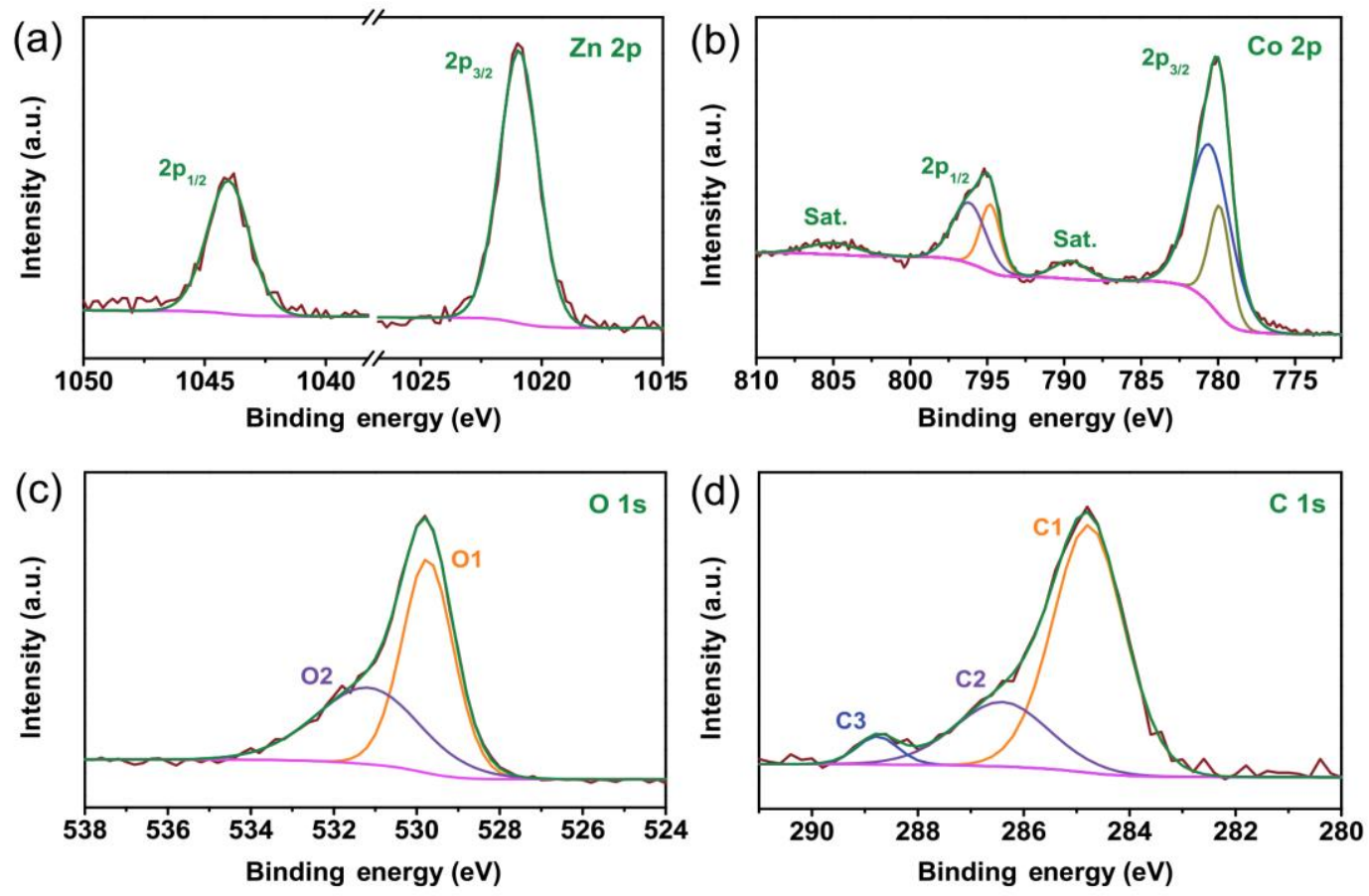

Fig. 4 XPS spectrums of Zn 2p (a), Co 2p (b), O 1s (c), C 1s (d) of $\mathrm{ZnCo}_{2} \mathrm{O}_{4} @ \mathrm{C}$. 
(a)

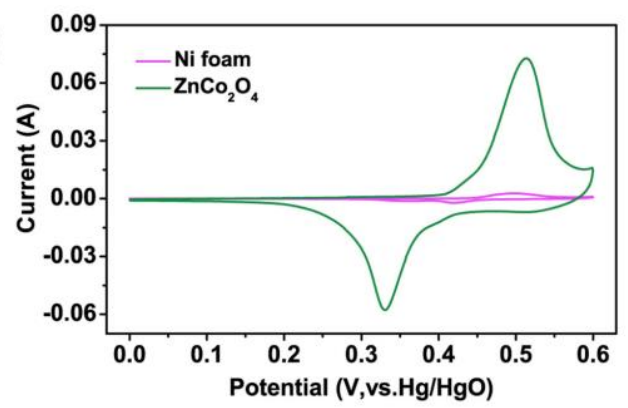

(c)

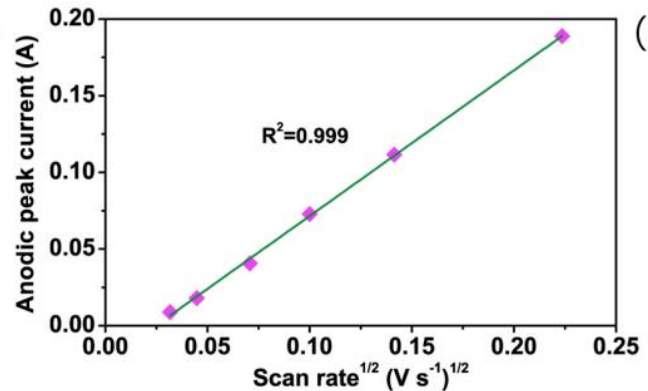

(b)

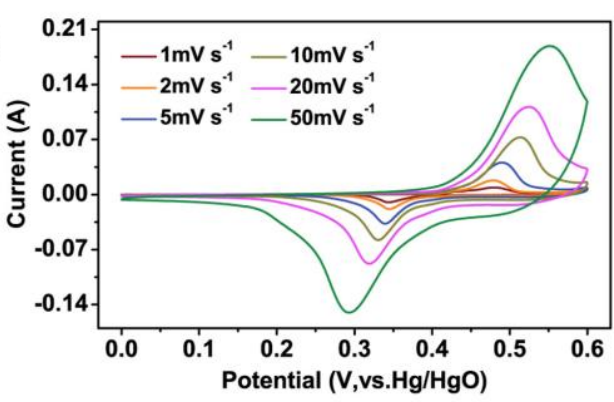

(d)

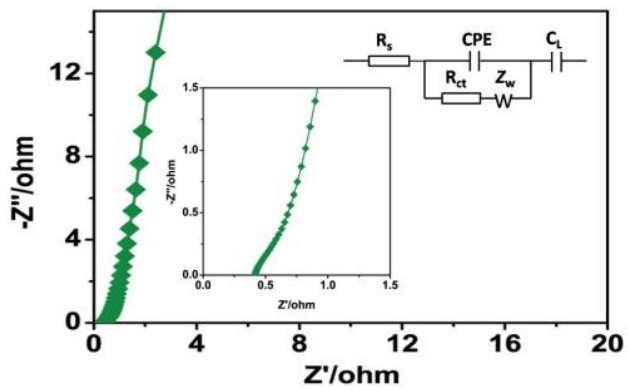

Fig. 5 Cyclic voltammograms $(\mathrm{a}, \mathrm{b})$ of the $\mathrm{ZnCo}_{2} \mathrm{O}_{4} @ \mathrm{C}$ electrode at a scan rate of 10 $\mathrm{mV} \mathrm{s}^{-1}$ with blank Ni foam as control (a), and at different scan rates (b); the relationship between the anodic peak current and the square root of the scan rate (c); EIS spectrum of the $\mathrm{ZnCo}_{2} \mathrm{O}_{4} @ \mathrm{C}$ electrode (d) (Inset, expanded view and the equivalent circuit). 
(a)

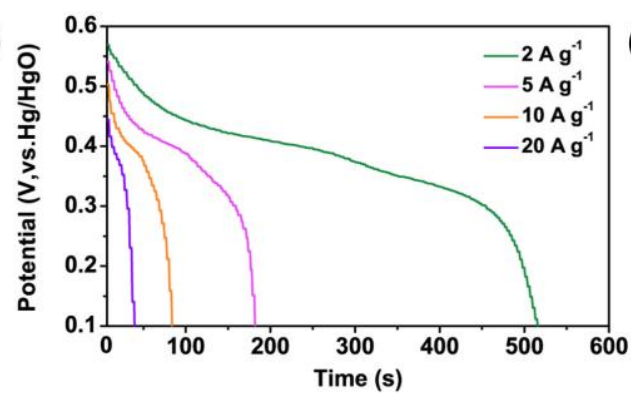

(c)

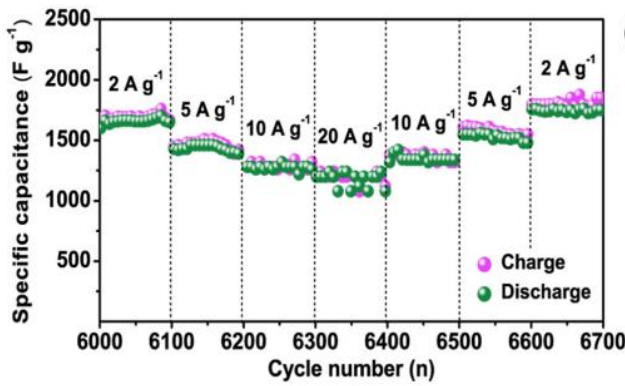

(b)

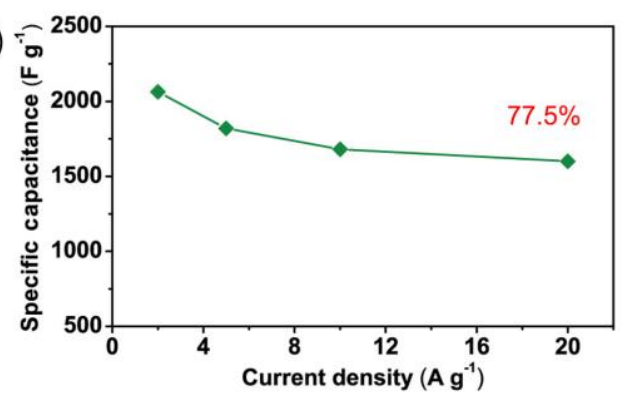

(d)

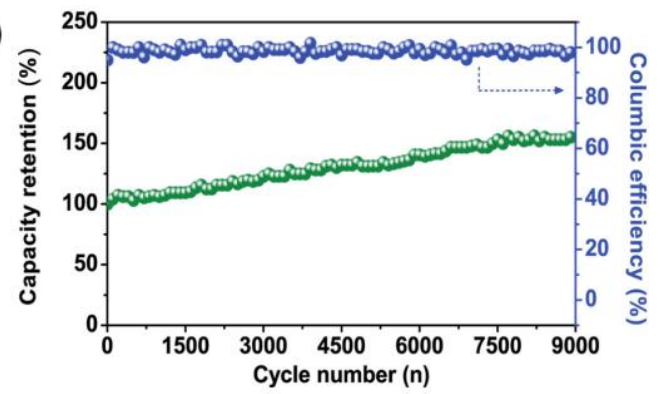

Fig. 6 Galvanostatic discharge curves (a), specific capacitance (b) and rate performance

(c) at various current densities of $\mathrm{ZnCo}_{2} \mathrm{O}_{4} @ \mathrm{C}$ electrode in $2 \mathrm{M} \mathrm{KOH}$; Cycling performance of $\mathrm{ZnCo}_{2} \mathrm{O}_{4} @ \mathrm{C}$ electrode at $5 \mathrm{~A} \mathrm{~g}^{-1}(\mathrm{~d})$. 
(a)

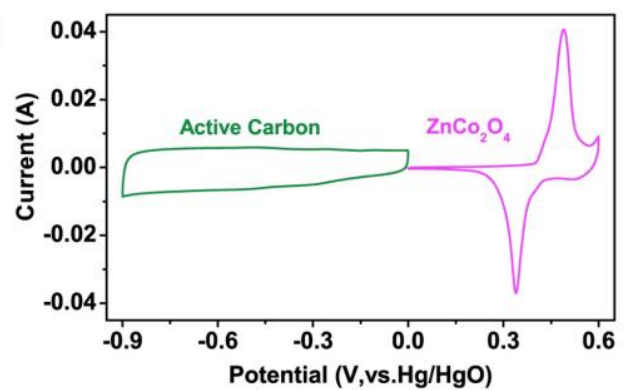

(c)

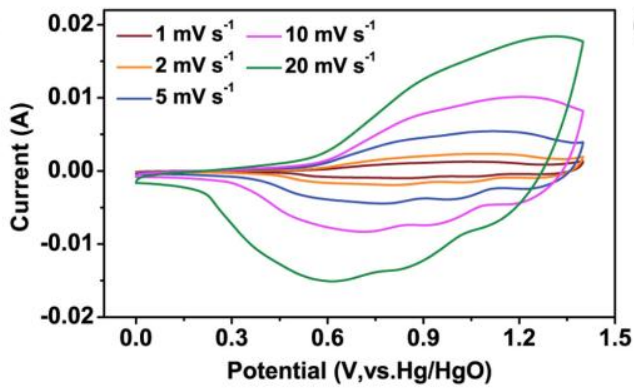

(e)

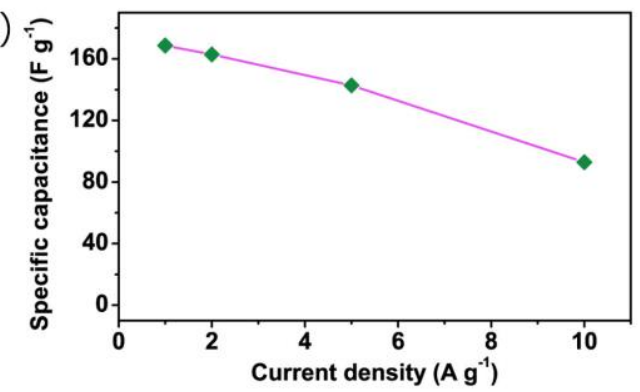

(b)

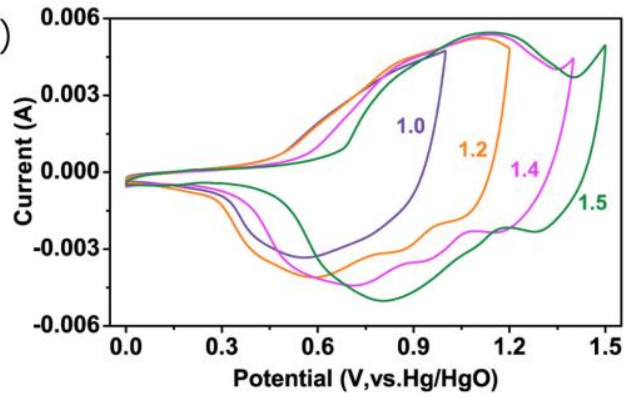

(d)

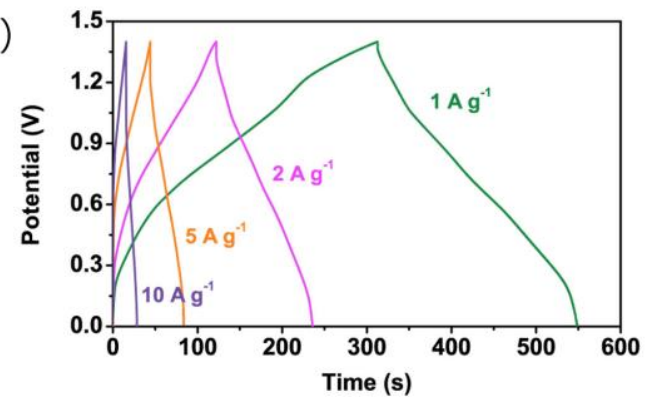

(f)

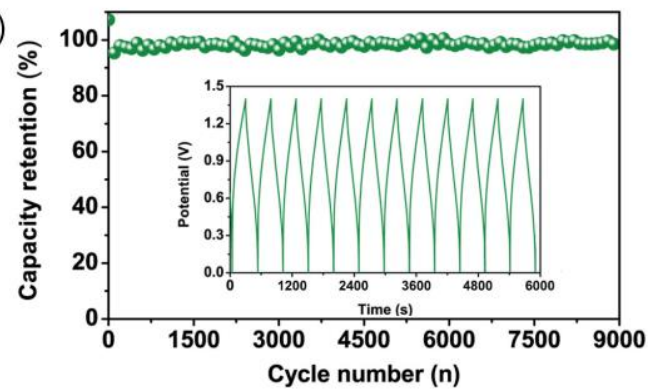

Fig. 7 Cyclic voltammograms (a-c) of the active carbon and $\mathrm{ZnCo}_{2} \mathrm{O}_{4} @ \mathrm{C}$ electrode(a), the $\mathrm{ZnCo}_{2} \mathrm{O}_{4} @ \mathrm{C} / / \mathrm{AC}$ asymmetric supercapacitor over different potential windows at a scan rate of $5 \mathrm{mV} \mathrm{s}^{-1}$ (b), the $\mathrm{ZnCo}_{2} \mathrm{O}_{4} @ \mathrm{C} / / \mathrm{AC}$ asymmetric supercapacitor over a potential window of 0 to $1.4 \mathrm{~V}$ at different scan rates (c); Charge-discharge curves (d), the corresponding specific capacitance at different current densities (e), and the cycling performance at $1 \mathrm{~A} \mathrm{~g}^{-1}(\mathrm{f})$ of the $\mathrm{ZnCo}_{2} \mathrm{O}_{4} @ \mathrm{C} / / \mathrm{AC}$ asymmetric supercapacitor (Inset, the last 12 charge-discharge cycles). 


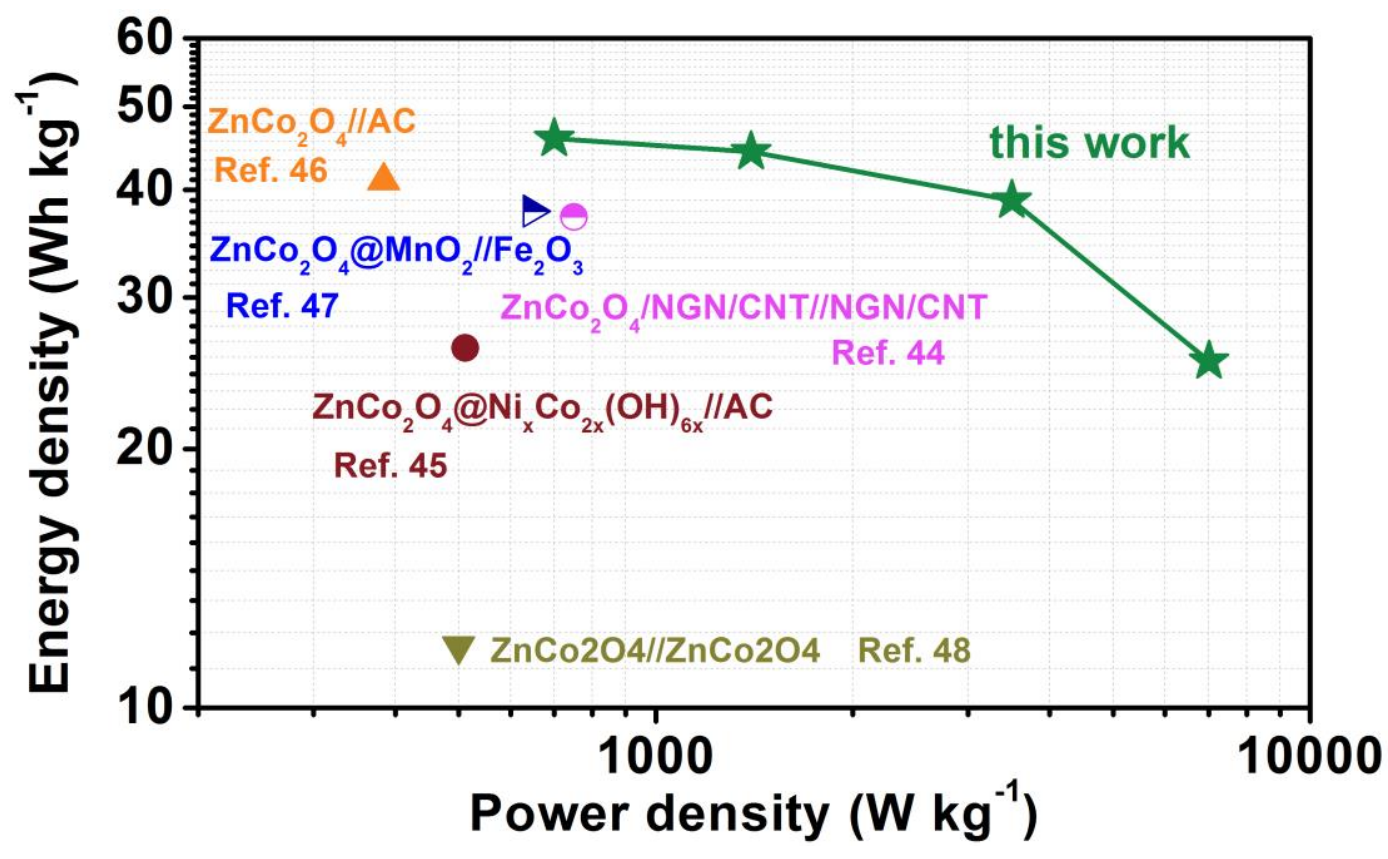

Fig. 8 Ragone plot of the $\mathrm{ZnCo}_{2} \mathrm{O}_{4} / / \mathrm{AC}$ asymmetric supercapacitor in comparison with the previously reported zinc cobaltite-based supercapacitors. 